\title{
Effects of Environment and Space on Species Turnover of Woody Plants across Multiple Forest Dynamic Plots in East Asia
}

OPEN ACCESS

Edited by:

Alessio Fini,

University of Florence, Italy

Reviewed by:

Ze-Xin Fan,

Xishuangbanna Tropical Botanical

Garden (CAS), China

Rachakonda Sreekar

University of Adelaide, Australia

*Correspondence:

Yongzhong Ye

yeyzh@163.com

tThese authors have contributed equally to this work.

Specialty section: This article was submitted to Functional Plant Ecology, a section of the journal Frontiers in Plant Science

Received: 05 July 2016 Accepted: 29 September 2016

Published: 13 October 2016

Citation:

Chen Y, Yuan Z, Li P, Cao R, Jia H and $Y e$ Y (2016) Effects of Environment and Space on Species Turnover of Woody Plants across Multiple Forest Dynamic Plots in East Asia. Front. Plant Sci. 7:1533. doi: 10.3389/fpls.2016.01533

\author{
Yun Chen ${ }^{1 \dagger}$, Zhiliang Yuan ${ }^{2 \dagger}$, Peikun $\mathrm{Li}^{2}$, Ruofan $\mathrm{Cao}^{2}$, Hongru $\mathrm{Jia}^{3}$ and Yongzhong $\mathrm{Ye}^{2 *}$ \\ ${ }^{1}$ College of Forestry, Henan Agricultural University, Zhengzhou, China, ${ }^{2}$ College of Life Sciences, Henan Agricultural \\ University, Zhengzhou, China, ${ }^{3}$ Educational Administration Department, Henan University of Finance and Banking, \\ Zhengzhou, China
}

Species turnover is fundamental for understanding the mechanisms that influence largescale species richness patterns. However, few studies have described and interpreted large-scale spatial variation in plant species turnover, and the causes of this variation remain elusive. In addition, the determinants of species turnover depend on the dispersal ability of growth forms. In this study, we explored the large-scale patterns of woody species turnover across the latitude gradient based on eight large stem-mapping plots (covering 184 ha forest) in East Asia. The patterns of woody species turnover increased significantly with increasing latitude differences in East Asia. For overall woody species, environment explained $36.30,37.20$, and $48.48 \%$ of the total variance in Jaccard's $\left(\beta_{\mathrm{j}}\right)$, Sorenson's, $\left(\beta_{\mathrm{s}}\right)$, and Simpson's dissimilarity $\left(\beta_{\text {sim }}\right)$. Spatial factors explained $47.92,48.39$, and $41.38 \%$ of the total variance in $\beta_{\mathrm{j}}, \beta_{\mathrm{S}}$, and $\beta_{\mathrm{sim}}$, respectively. The effects of pure spatial and spatially structured environments were stronger than pure environmental effects for overall woody species. Our results support the hypothesis that the effect of neutral processes on woody species turnover is more important than the effect of the environment. Neutral processes explained more variation for turnover of tree species, and environmental factors explained more variation for the turnover of shrub species on a large scale. Therefore, trees and shrubs should be subjected to different protection strategies in future biodiversity conservation efforts.

Keywords: climate, environmental, latitudinal gradient, neutral processes, growth forms

\section{INTRODUCTION}

Species turnover pattern (or beta diversity) is a basic pattern in biogeography and macroecology (Gaston, 2000), and it provides fundamental insights into mechanisms of community assembly, especially on a large scale (Anderson et al., 2011). However, species turnover patterns have received less attention than alpha diversity (Koleff et al., 2003), and most studies on species turnover have been conducted locally (Kraft et al., 2011; Wang et al., 2012a). On a large scale, recent studies have demonstrated that species spatial turnover is a key factor for both plants and animals (Kreft and Jetz, 2007; Qian and Ricklefs, 2008). Stuart et al. (2012) have found that the environmental dissimilarity coefficient of lizards and frogs increased with changing geographical distance and habitat; Qian et al. (2009) have shown that the similarity coefficients of North American mammals and African amphibians decrease with increasing spatial distance. However, the studies on the 
patterns of species turnover across latitudes are relatively few. Moreover, in the few studies about the patterns of species turnover across latitudes, a great majority is based on the space-filling species of range maps. The drawbacks of this method include coarse spatial resolutions; spatial heterogeneity among species composition has been smoothed out, and spatial autocorrelation has increased (Wang et al., 2012b).

The underlying mechanisms governing large-scale species turnover are ambiguous and poorly studied (De Cáceres et al., 2012) despite several and recent efforts to describe large-scale species turnover patterns of plant (De Cáceres et al., 2012; Tang et al., 2012a,b; Wang et al., 2012b; Xu et al., 2015). Several research studies have indicated that species coexistence is attributed to different environmental factors; species have different resources, time, and space to achieve coexistence (Jia et al., 2015; Escudero and Valladares, 2016). Alternatively, neutral processes state that species coexistence results from biogeographic barriers and low dispersal abilities (Hubbell, 2001; Jia et al., 2015). Moreover, results vary because of differences in the methods, including the spatial extents and the measures of species turnover. Therefore, the relative role of the environment and neutral processes in governing species turnover may vary (Liu et al., 2015; Valladares et al., 2015).

The dispersal ability of plant species is frequently predicted to influence species turnover, but only limited tests have been performed to confirm this; the results of these tests have been inconsistent (Qian, 2009; Elgar et al., 2014). For example, Bin et al. (2010) studied the Dinghushan plot and indicated that shrubs had weaker dispersal limitations than arbors and subarbors. Guèze et al. (2013) studied seven villages in the southwestern Amazon and indicated that the floristic patterns of large trees were explained more by environmental variables; those of small trees were explained more by geographical distances. Moreover, the large-scale dispersal ability among growth forms has been studied to a lesser degree, especially in terms of mechanism.

China, which possesses various tropical and temperate areas, provides ideal environments for investigating large-scale biodiversity patterns (Fang et al., 2012). Over the past decade, the Chinese Forest Biodiversity Monitoring Network ${ }^{1}$ established large stem-mapping plots located along a latitudinal gradient from temperate to subtropical and tropical forests (De Cáceres et al., 2012; Erickson et al., 2014; Song et al., 2015). Furthermore, two large stem-mapping plots were established by the Forestry research institution in Taiwan (Song et al., 2015). Here, we exploit this opportunity and analyze the turnover of woody species across temperate, subtropical, and tropical forests based on eight large stem-mapping plots.

The objectives of the current study are as follows: (1) to obtain an integrated analysis of the similarity of species composition among eight large stem-mapping plots; (2) to identify the patterns of species turnover along the latitude difference using three measures of species turnover; and (3) to assess the relative influence of environmental and neutral processes on species turnover of overall woody species and growth forms.

${ }^{1}$ http://www.cfbiodiv.org/

\section{MATERIALS AND METHODS}

\section{Study Sites}

In this study, eight large stem-mapping plots were selected, as follows: the Lianhuachi, Fushan, Xishuangbanna, Dinghushan, Badagongshan, Gutianshan, Tiantongshan, and Changbaishan plots. Distributions of these eight plots are shown in Figure 1. The latitude of the plots cross ranges from 21.61 to $42.38^{\circ}$, and the average elevation ranges from 350.0 to $1405.5 \mathrm{~m}$. The community type includes tropical rain forests, subtropical evergreen broadleaved forests, and temperate deciduous broad-leaved forests. Census methodologies were the same for all plots: all trees with a diameter at breast height $\geq 1 \mathrm{~cm}$ were tagged and identified.

\section{Species and Environment Variables}

In the study, we used data on the species catalog, the longitude and latitude of the plots, topographical factors [mean slope $\left(\mathrm{MS},{ }^{\circ}\right)$, mean elevation ( $\left.\mathrm{ME}, \mathrm{m}\right)$, highest elevation ( $\left.\mathrm{HA}, \mathrm{m}\right)$, lowest elevation (LE, m)], and climate factors [mean annual precipitation (MAP, $\mathrm{mm}$ ), relative humidity ( $\mathrm{RH}, \%)$, mean annual temperature $\left(\mathrm{MAT},{ }^{\circ} \mathrm{C}\right)$, and the mean temperature of the warmest (MTWM, ${ }^{\circ} \mathrm{C}$ ) and coldest months (MTCM, $\left.\left.{ }^{\circ} \mathrm{C}\right)\right]$. The species catalog was obtained from literature. Longitude and latitude, topographical factors, and climate factors were obtained from the Chinese Forest Biodiversity Monitoring Network or literature (Su et al., 2007; Hao et al., 2008; Lan et al., 2008; Lin et al., 2011; Yuan et al., 2011; Song et al., 2015). The topographical factors of the Tiantongshan plot were obtained according to the topographic map in the Biodiversity Monitoring Network; and calculation methods were based on the methods by Harms et al. (2001) and Valencia et al. (2004). Information on geography and climate for the eight study sites are shown in Table $\mathbf{1 .}$

The eight plots differed in established time, region, and researchers. Thus, plant identification varied among plots. Thus, the species names in the plots were checked based on the Flora Reipublicae Popularis Sinicae (1959-2004) and Catalogue of Life China (2013). Concurrently, all species were divided into three types, namely, trees, small trees, and shrubs, based on the records of the Flora Reipublicae Popularis Sinicae (19592004).

Studies that used $20 \mathrm{~m} \times 20 \mathrm{~m}$ subplots as basic units have shown that the species-area curves of all the forest community types in China are smooth for about 6 ha, which includes most of the species in the region (Hao et al., 2008; Lan et al., 2008; Zhu et al., 2008; Yang et al., 2011). In this study, every plot has an area greater than 20 ha. Thus, every plot can reflect the profile of the species composition in the region. Furthermore, the smallest plot area is $20 \mathrm{ha}$, and the largest is $25 \mathrm{ha}$; thus, the effect of area difference on large-scale species composition among plots is negligible.

\section{Measurement of Species Turnover Rate}

Species turnover rate is the rate of dissimilarity among species composition across all possible plot pairs along the environmental gradient. The slope of the relationship between the species turnover and environmental divergence measures 


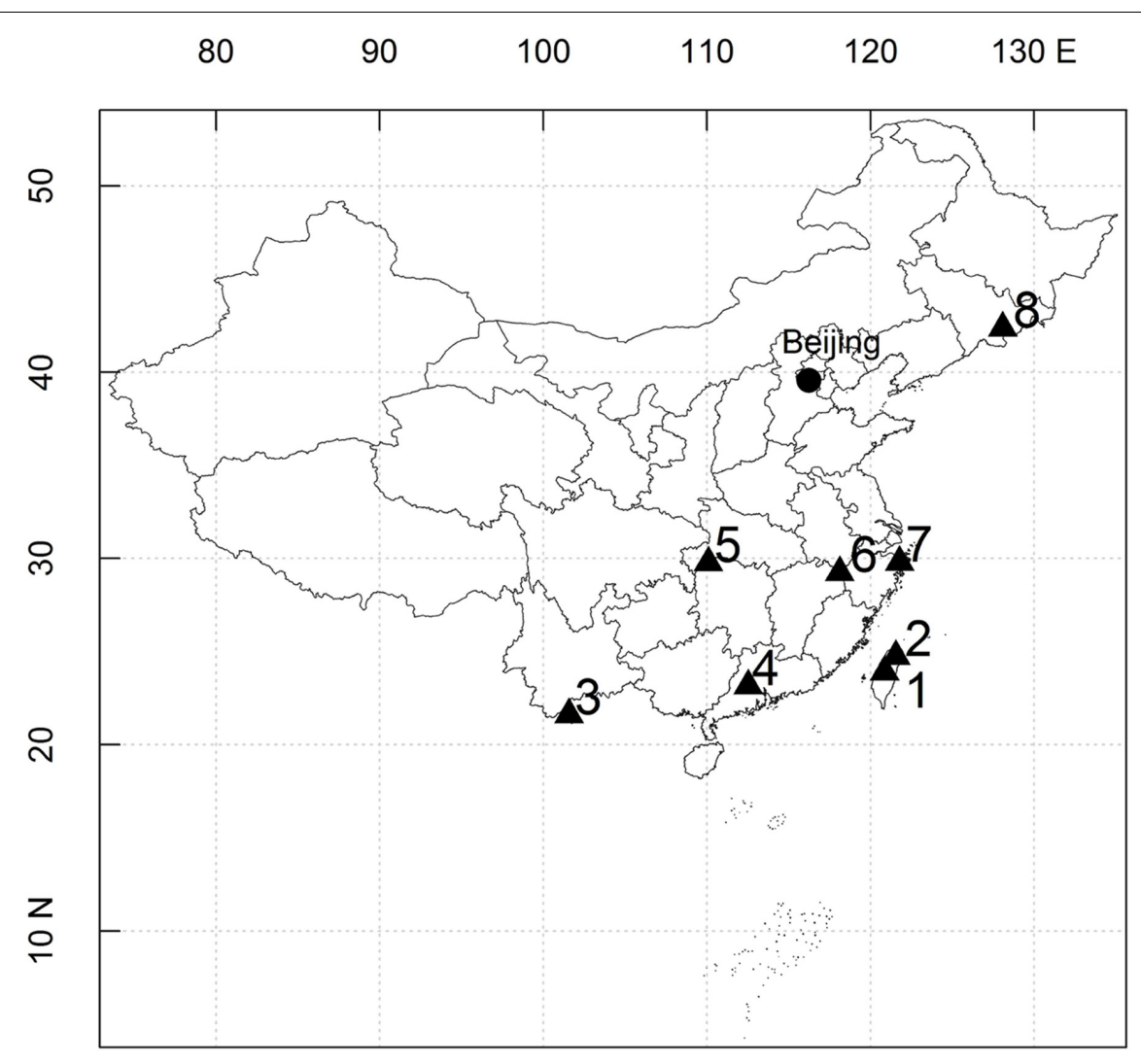

FIGURE 1 | Location of eight dynamics plots in East Asia. (1) Lianhuachi plot; (2) Fushan plot; (3) Xishuangbanna plot; (4) Dinghushan plot; (5) Badagongshan plot; (6) Gutianshan plot; (7) Tiantongshan plot; (8) Changbaishan plot.

species turnover rate. Jaccard's index ( $\beta_{\mathrm{j}}$; Jaccard, 1912), Sorenson's index $\left(\beta_{s}\right.$; Sorensen, 1948), and Simpson's index ( $\beta_{\text {sim }}$; Lennon et al., 2001) measure turnover rate of species composition. $\beta_{\mathrm{j}}$ and $\beta_{\mathrm{s}}$ are two widely employed indices and are independent of $\alpha$-diversity (Jost, 2007). $\beta_{\text {sim }}$ controls for local gradients in species richness (Lennon et al., 2001; Wang et al., 2012b).

$$
\begin{aligned}
& \beta_{\mathrm{j}}=1-c /(a+b+c)=(a+b) /(a+b+c) \\
& \beta_{\mathrm{s}}=1-2 c /(a+b+2 c)=(a+b) /(a+b+2 c) \\
& \beta_{\operatorname{sim}}=1-c /[\min (a, b)+c]=\min (a, b) /[\min (a, b)+c]
\end{aligned}
$$

where $a$ and $b$ are the numbers of species only occurring in the focal and neighboring plots, respectively, and $c$ is the number occurring in both.

\section{Data Analysis}

We used detrended correspondence analysis (DCA) for the ordination of plots. DCA is an effective method in vegetation analysis. In our study, we conducted DCA using a plot-species matrix using relative abundance data to analyze the similarity of the species composition among

\begin{tabular}{|c|c|c|c|c|c|c|c|c|}
\hline Plot name & $\begin{array}{l}\text { Plot size } \\
\text { (ha) }\end{array}$ & $\begin{array}{l}\text { Latitude } \\
\quad\left({ }^{\circ}\right)\end{array}$ & $\begin{array}{l}\text { Longitude } \\
\left(^{\circ}\right)\end{array}$ & $\begin{array}{c}\text { Mean } \\
\text { elevation (m) }\end{array}$ & $\begin{array}{c}\text { Mean slop } \\
\left(^{\circ}\right)\end{array}$ & $\begin{array}{c}\text { Mean annual } \\
\text { temperature }\left({ }^{\circ} \mathrm{C}\right)\end{array}$ & $\begin{array}{c}\text { Mean annual } \\
\text { Precipitation (mm) }\end{array}$ & $\begin{array}{c}\text { Relative } \\
\text { humidity (\%) }\end{array}$ \\
\hline Lianhuachi plot & 25 & 23.90 & 120.87 & 756.00 & 35.00 & 25.0 & 2211.0 & 95.0 \\
\hline Fushan plot & 25 & 24.75 & 121.55 & 675.00 & 10.00 & 18.3 & 4237.0 & 95.0 \\
\hline Xishuangbanna plot & 20 & 21.61 & 101.57 & 789.21 & 11.33 & 21.8 & 1493.0 & 85.0 \\
\hline Dinghushan plot & 20 & 23.17 & 112.52 & 350.00 & 40.00 & 20.9 & 1985.0 & 80.3 \\
\hline Badagongshan plot & 25 & 29.77 & 110.09 & 1405.50 & 36.00 & 11.5 & 2105.4 & 90.0 \\
\hline Gutianshan plot & 24 & 29.25 & 118.12 & 580.60 & 37.00 & 15.3 & 1963.7 & 92.4 \\
\hline Tiantongshan plot & 20 & 29.80 & 121.78 & 447.25 & 31.50 & 16.2 & 1374.7 & 82.0 \\
\hline Changbaishan plot & 25 & 42.38 & 128.08 & 801.50 & 2.23 & 3.6 & 700.0 & 78.0 \\
\hline
\end{tabular}
plots.

TABLE 1 | Information on geography and climate for eight study sites. 
Environmental variables: We used the climate and topographical factors to determine the environmental divergence between pairs of sites: MAP, RH, MAT, MTWM, MTCM, MS, ME, MA, and LE. All environmental variables were normalized as: $x^{\prime}=(x-\operatorname{mean}(x)) /$ standard deviation $(x)$, where $x$ is a variable. Several studies have shown that most environmental variables are highly correlated with each other in China (Wang et al., 2012a). To avoid strong multicollinearity in regression models, we did not use original environmental variables as response variables. Instead, we conducted a principle component analysis (PCA) for all environmental variables and extracted the first six PC axes, which contained $95.19 \%$ of the total variance in the original environmental variables. In addition, longitude and latitude data of all the plots as shown in Table $\mathbf{1 .}$ Latitude difference is the difference in latitude values between the plot-pair.

Spatial variables: In our study, principal coordinates of neighbor matrices (PCNM) were used to obtain the spatial variable as a response variable based on the latitude and longitude of each plot. PCNM variables represent the spatial relationship among sites more accurately than Euclidean distance matrix and geographic coordinates (Legendre et al., 2009).

To account for effects of variation in $\gamma$-diversity, we explored the relationship between $\beta$ - and $\gamma$-diversities using simple regression, with significance at $p<0.05$. $\gamma$-Diversity is the number of species occurring in each plot-pair. Moreover, a null modeling approach was used to calculate the $\beta$-deviation according to Kraft et al. (2011). $\beta$-Deviation is currently the most widely used method (Myers et al., 2013).

To explore the influence of environment and space on $\beta$-diversity, we adopted multiple generalized linear models (GLM) using the calculated $\beta_{\mathrm{j}}, \beta_{\mathrm{s}}$, and $\beta_{\text {sim }}$ as dependent, and aforementioned environment (MAP, RH, MAT, MTWM, MTCM, MS, ME, MA, and LE) and PCNM variables as response variables. The adjusted $R^{2}$ of a model is used to represent the explanatory power of environmental and PCNM variables on species turnover. To avoid overestimation resulting from a large number of response variables, we compared the values of the Akaike information criterion (AIC) to select the best environmental model and spatial model separately. For models with the same number of variables, the model with the smallest AIC was selected. Model selection stopped when any added variable increased the AIC (Tang et al., 2012b).

Partial regression analyses were used to further compare the effects of environmental and spatial processes. In the partial regression analyses, $\beta_{\mathrm{j}}, \beta_{\mathrm{s}}$, and $\beta_{\text {sim }}$ were dependent, and environment variables (MAP, RH, MAT, MTWM, MTCM, MS, ME, MA, and LE) and PCNM variables were the response variables. Partial regression divided the variance in species turnover index into four parts: pure spatial effects, pure environmental effects, spatially structured environmental effects, and residual variance.

All analyses were conducted in R 2.15 (R Core Development Team ${ }^{2}$ ). DCA and PCA were performed using the "vegan"

${ }^{2}$ http://www.Rproject.org package (Oksanen et al., 2007). PCNM was performed using the "pcnm" package (Blanchet et al., 2008).

\section{RESULTS}

\section{Structural Characteristics of Plant Community}

A total of 1025 woody species were included in the final dataset, encompassing 355 genera in 100 families. We classified all plots into three vegetation types based on their thermal characteristics and water availability, as follows: tropical rain forest, subtropical evergreen broad-leaved forest, and temperate deciduous broad-leaved forest (Figure 2A). The species diversity differed significantly among forest types. Among the eight plots, the Xishuangbanna plot belonged to the tropical rain forest; therefore, its species diversity is the highest among all plots (Overall: 365, tree: 239, small tree: 89, shrub: 37). The Changbaishan plot belonged to the temperate deciduous broadleaved forest. Therefore, its species diversity is the lowest among all plots (Overall: 52, tree: 26, small tree: 9, shrub: 17; Figure 2B).

The result of plot ordination is shown in Figure 3 . The similarity between the Lianhuachi and Fushan plots is the highest in species composition. The similarities among the Dinghushan, Badagongshan, Gutianshan, and Tiantongshan plots are highest in species composition. The similarities between the Changbaishan and the other seven plots are the smallest because of far distance and large environmental differences.

\section{Patterns of Species Turnover}

$\beta_{j}, \beta_{s}$, and $\beta_{\text {sim }}$ increased significantly with increasing latitude difference of overall species, trees, small trees, and shrubs. The species turnover rates that crossed the latitudinal difference were $0.030,0.056$, and 0.076 for $\beta_{\mathrm{j}}, \beta_{\mathrm{s}}$, and $\beta_{\text {sim }}$ of overall woody species; $0.030,0.055$, and 0.070 for $\beta_{\mathrm{j}}, \beta_{\mathrm{s}}$, and $\beta_{\text {sim }}$ of trees; $0.038,0.071$, and 0.102 for $\beta_{\mathrm{j}}, \beta_{\mathrm{s}}$, and $\beta_{\text {sim }}$ of small trees; and $0.020,0.038$, and 0.050 for $\beta_{\mathrm{j}}, \beta_{\mathrm{s}}$, and $\beta_{\text {sim }}$ of shrubs, respectively (Figure 4). The species turnover rate of shrubs was less than that of trees and small trees along the latitudinal difference. The number of species declined significantly with increasing latitude of overall woody species, trees, small trees, and shrubs.

\section{Relationship between $\beta$ - and $\gamma$-Diversity}

$\gamma$-diversity did not significantly affect $\beta_{\mathrm{j}}, \beta_{\mathrm{s}}$, and $\beta_{\text {sim }}$ for overall species, trees, small trees, and shrubs (Figures 5A-D). Moreover, $\beta$-deviation increased along latitudinal difference for overall species $\left(R^{2}=0.66\right)$, trees $\left(R^{2}=0.58\right)$, small trees $\left(R^{2}=0.67\right)$, and shrubs $\left(R^{2}=0.54\right.$; Figure $\left.5 \mathrm{E}\right)$. Therefore, after correcting the differences in species pool size ( $\gamma$-diversity), $\beta$-diversity had significant difference along latitudinal difference.

\section{Determinants of Species Turnover}

The first six PC axes and four PCNM variables were used to assess the effects of the environment and space. The best environmental models and spatial models are shown in Table 2. For overall woody species, environment explained 36.30 , 37.20, and $48.48 \%$ 

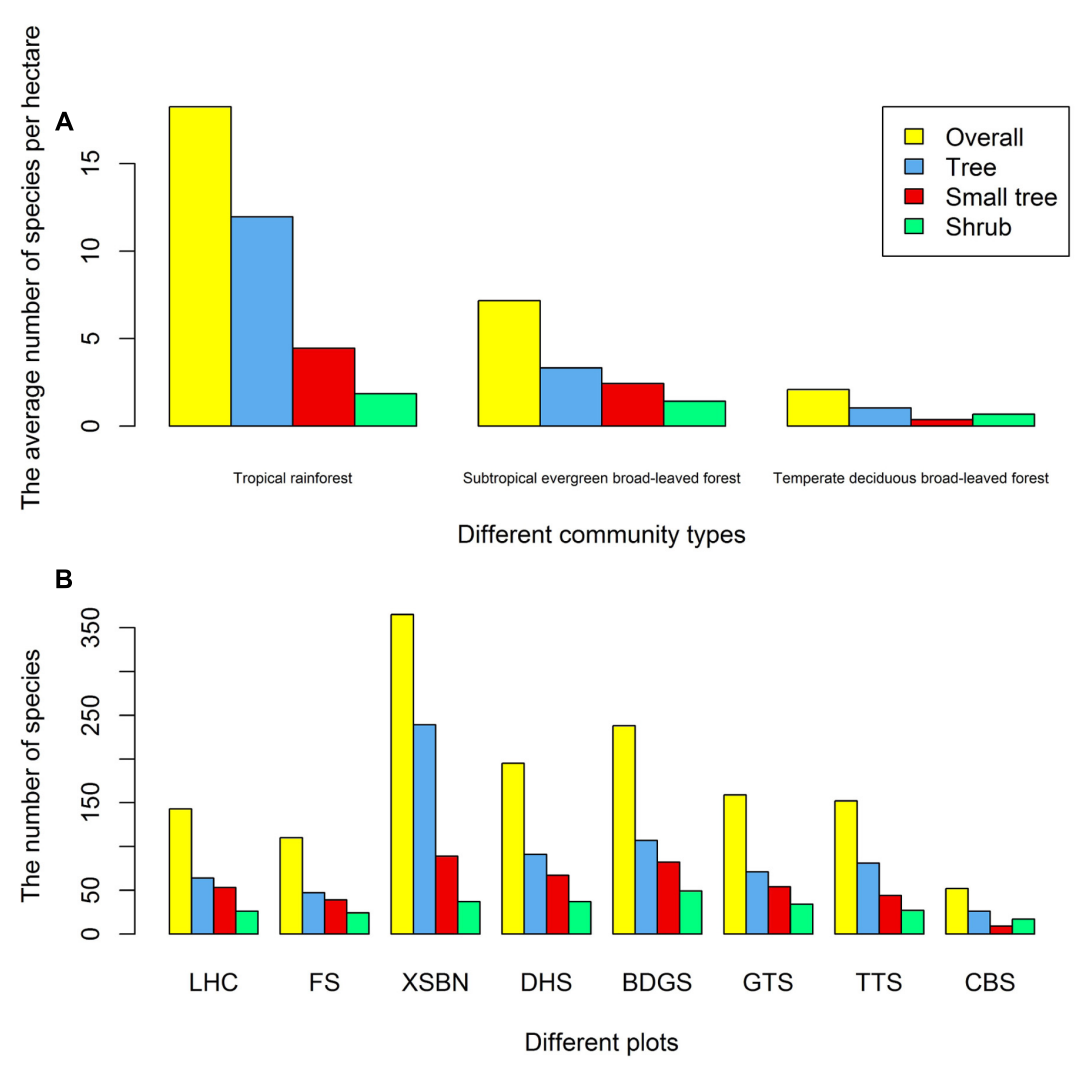

FIGURE 2 | Number of species in different community types (A) or different plots (B). Abbreviations: LHC, Lianhuachi plot; FS, Fushan plot; XSBN, Xishuangbanna plot; DHS, Dinghushan plot; BDGS, Badagongshan plot; GTS, Gutianshan plot; TTS, Tiantongshan plot; CBS, Changbaishan plot.

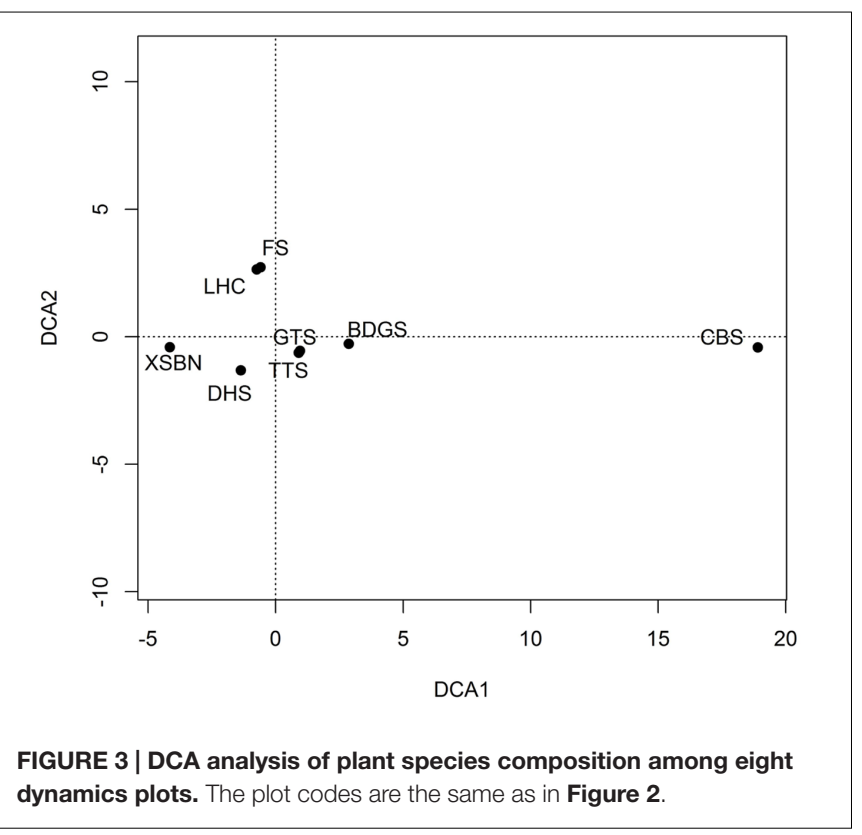

of the total variance in $\beta_{\mathrm{j}}, \beta_{\mathrm{s}}$, and $\beta_{\mathrm{sim}}$, respectively; and spatial factors explained $47.92,48.39$, and $41.38 \%$ of the total variance in $\beta_{\mathrm{j}}, \beta_{\mathrm{s}}$, and $\beta_{\text {sim }}$, respectively.
Partial regressions indicated that the effects of pure spatial and spatially structured environments on $\beta_{\mathrm{j}}, \beta_{\mathrm{s}}$, and $\beta_{\text {sim }}$ were stronger than those of pure environmental factors for overall woody species (Figure 6). For trees and small trees, the effects of pure spatial and spatially structured environmental factors on $\beta_{\mathrm{j}}, \beta_{\mathrm{s}}$, and $\beta_{\mathrm{sim}}$ were stronger than those of pure environmental factors, whereas the effects of pure environmental factors on $\beta_{\mathrm{j}}, \beta_{\mathrm{s}}$, and $\beta_{\text {sim }}$ were stronger than those of pure spatial and spatially structured environmental factors for shrubs. Moreover, the effects of pure environmental factors on $\beta_{\mathrm{j}}, \beta_{\mathrm{s}}$, and $\beta_{\text {sim }}$ for trees were the lowest, and the effects of pure environmental for shrubs were the highest.

\section{DISCUSSION}

Large stem-mapping plots have been established in different regions worldwide (Erickson et al., 2014). Many scholars have studied large stem-mapping plots, such as functional traits (Liu et al., 2016) and species coexistence mechanisms (AielloLammens et al., 2016). However, most of these studies were conducted in local areas, and integrated large-scale analyses have been poorly studied. Various ecosystems worldwide are interconnected. Thus, integrating comparative large scale analyses can reveal the rules of forest community distributions 

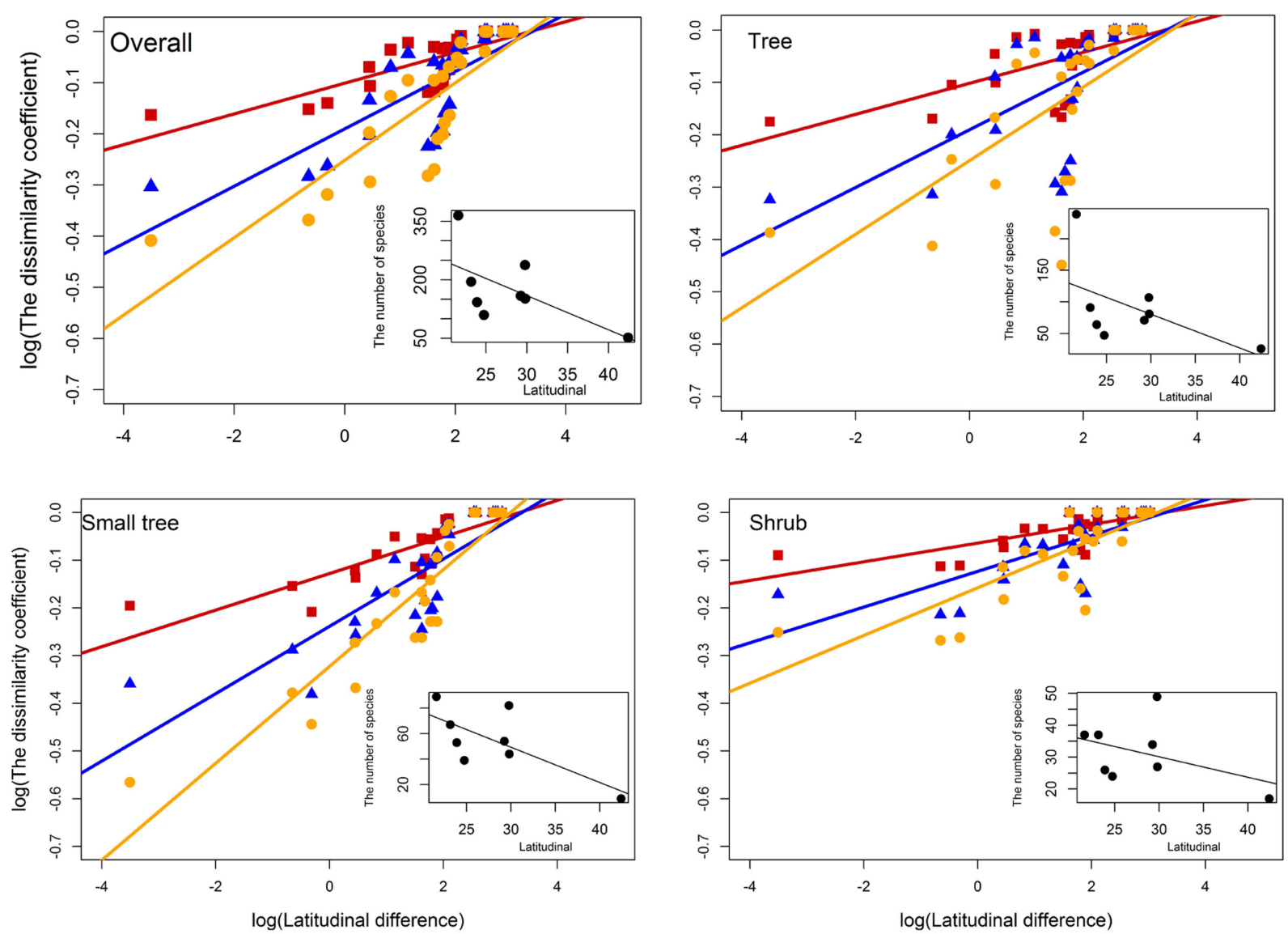

FIGURE 4 | Patterns of overall species turnover $\left(\beta_{\mathrm{j}}: \boldsymbol{R}=0.5895^{* * *} ; \beta_{\mathrm{s}}: \boldsymbol{R}=0.5824^{* * *} ; \beta_{\mathrm{sim}}: \boldsymbol{R}=0.6929^{* * *}\right)$, trees $\left(\beta_{\mathrm{j}}: \boldsymbol{R}=0.4009^{* * *} ; \beta_{\mathrm{s}}: \boldsymbol{R}=0.4011^{* * *}\right.$; $\left.\beta_{\text {sim }}: R=0.4144^{* * *}\right)$, small trees $\left(\beta_{\mathrm{j}}: R=0.6859^{* * *} ; \beta_{\mathrm{s}}: R=0.6764^{* * *} ; \beta_{\text {sim }}: R=0.8175^{* * *}\right)$, and shrubs $\left(\beta_{\mathrm{j}}: R=0.5250^{* * *} ; \beta_{\mathrm{s}}: R=0.5247^{* * *} ; \beta_{\text {sim }}:\right.$

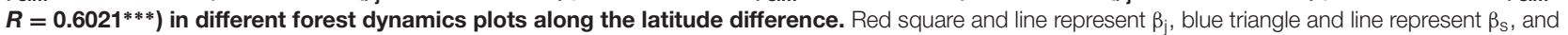
yellow dot and line represent $\beta_{\text {sim. }}$. The subset shows the relationship between the number of species and latitudinal across multiple forest dynamics plots. Latitude difference is the difference in latitude values between the plot-pair.

and species coexistence mechanisms. In this study, we used comparative analysis to analyze the species composition similarities of eight large forest plots. As expected, smaller distances between the plots tended to increase similarity in species composition. Moreover, species diversity decreased with increasing latitude.

Several studies have shown that species diversity generally increases with decreasing latitude (Rodríguez and Arita, 2004; Qian and Ricklefs, 2007; Kraft et al., 2011; Wang et al., 2012b). However, different methods, including the sampling scale and measures of species turnover, have been used in different studies. Sampling scale in previous studies usually were small plots (e.g., $10 \mathrm{~m} \times 10 \mathrm{~m}$ or $20 \mathrm{~m} \times 20 \mathrm{~m}$ ), and the sampling scales in this study were 20 or 25 ha plots. Moreover, measures of species turnover in previous studies usually used one method. To avoid the error caused by using different methods of measurement, three different methods were employed to measure the species turnover rate. Based on the forest dynamics plots in this study, the patterns of species turnover increased significantly with increasing latitude differences for $\beta_{\mathrm{j}}, \beta_{\mathrm{s}}$ and $\beta_{\text {sim }}$ of overall woody species, trees, small trees, and shrubs, respectively. These results are consistent with those obtained in previous studies (Rodríguez and Arita, 2004; Qian and Ricklefs, 2007; Kraft et al., 2011; Wang et al., 2012b). The reasons for the increase in species turnover rate with increasing latitude differences are complicated; among the reasons, latitudinal gradients in climatic tolerance and sampling effect of the species pool are the most reported (Wang et al., 2012b; Morin and Lechowicz, 2013). The hypothesis of latitudinal gradients in climatic tolerance claims that species are more climatically tolerant in high than in low latitudes. Lower climatic tolerance may further lead to narrower niche breadths in tropical than in temperate mountains, thereby decreasing the likelihood of co-occurrence of different species and increasing the species turnover rate (Wang et al., 2012b; Morin and Lechowicz, 2013).

The sampling effect hypothesis claims that variation in $\beta$-diversity across broad biogeographic gradients is more likely to be driven by $\gamma$-diversity than by differences in the mechanisms of community assembly (Kraft et al., 2011; Myers et al., 2013; $\mathrm{Xu}$ et al., 2015). In the present study, species pool did not significantly affect the pattern of species turnover for overall 
A

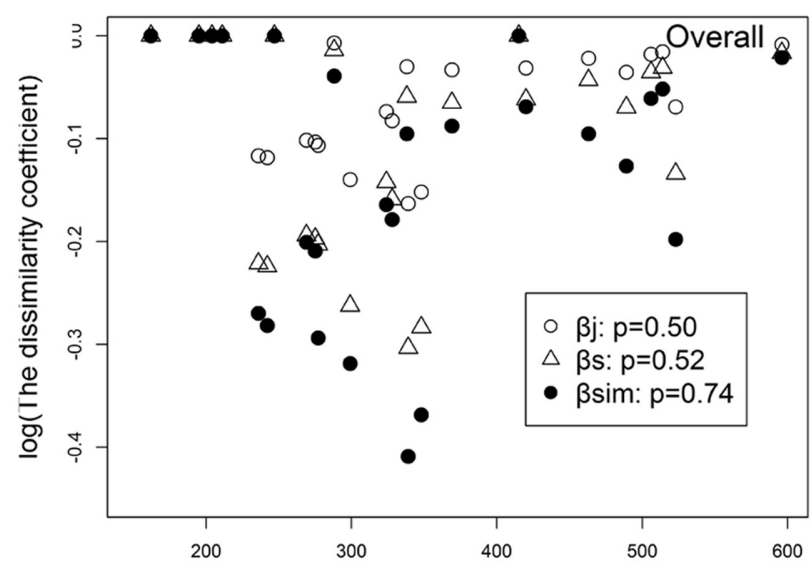

C

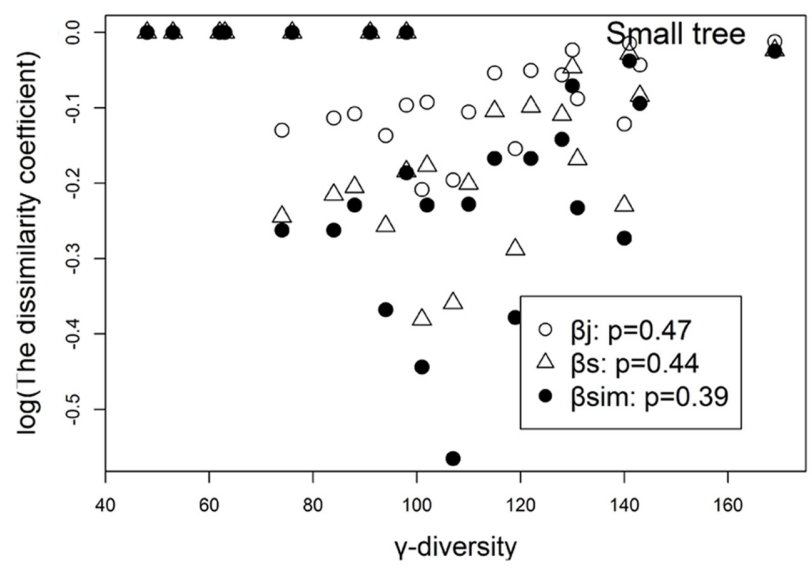

B

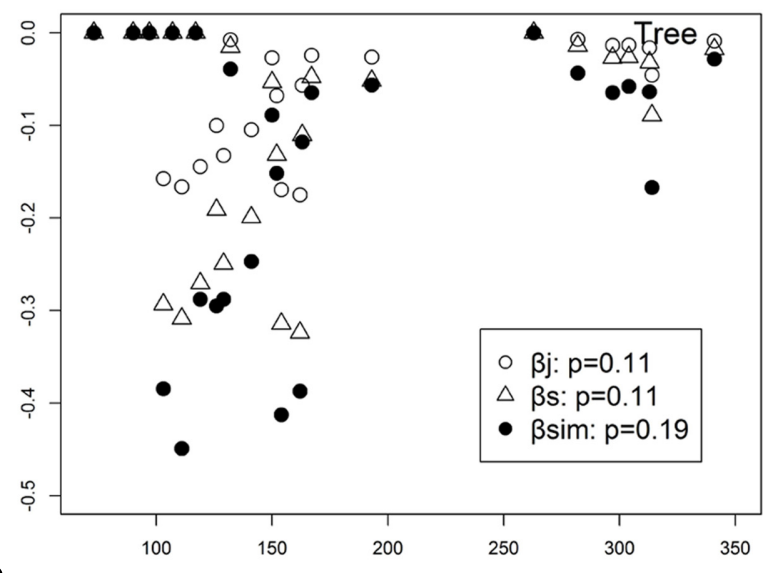

D

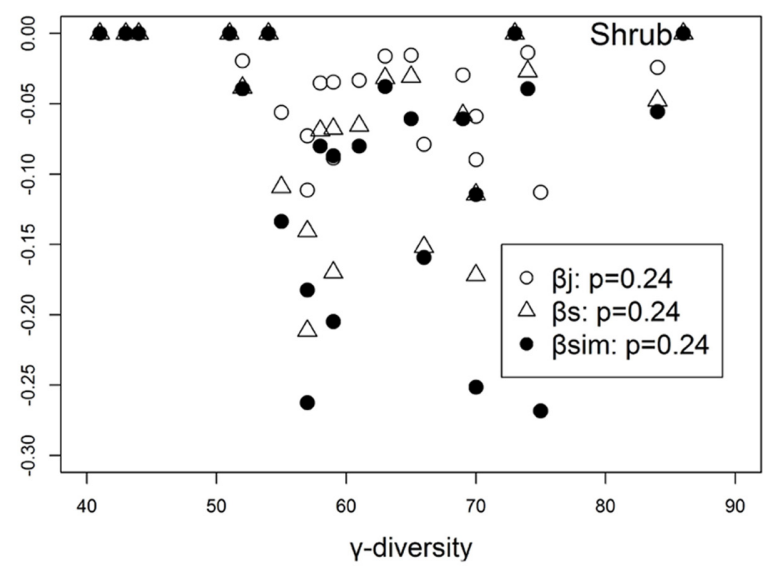

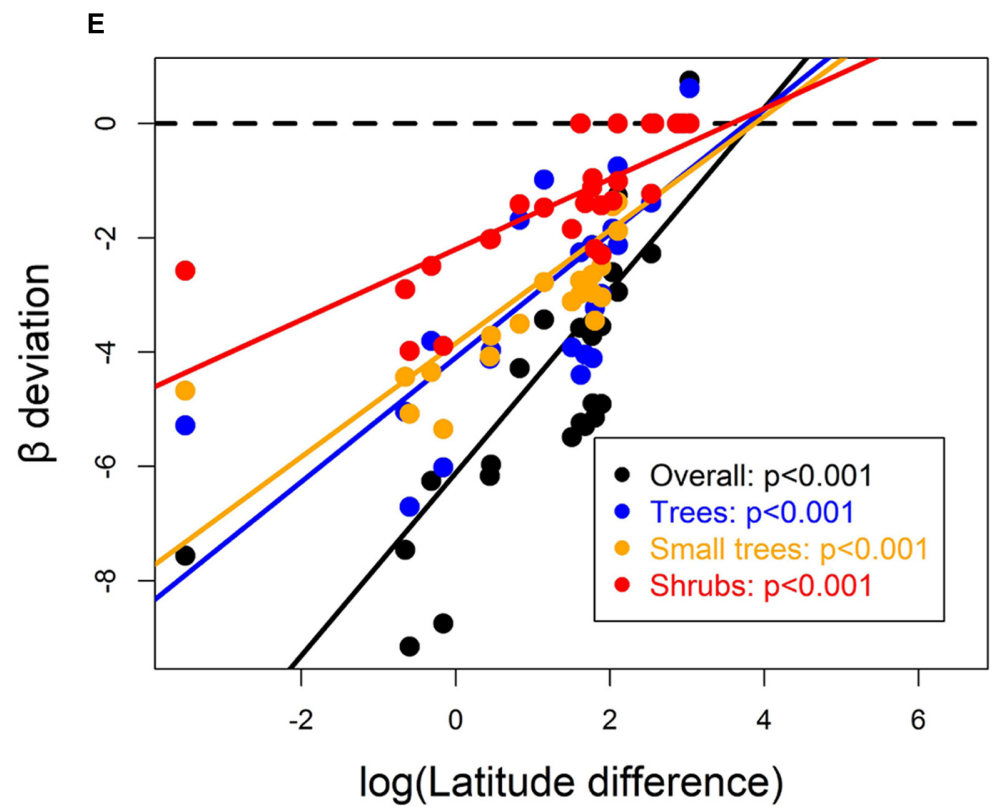

FIGURE 5 | Relationship between $\beta$ - and $\gamma$-diversities for (A) overall, (B) tree, (C) small tree, and (D) shrub. Open dots represent $\beta_{j}$, gray triangles represent $\beta_{\mathrm{s}}$, and solid dots represent $\beta_{\mathrm{sim}}$. A standard effect size of $\beta$-diversity deviations from a null model that corrects for $\gamma$ dependence across with latitude difference (E). 
TABLE 2 | Relationships between $\beta$-diversity and PC variables or PCNM variables.

\begin{tabular}{|c|c|c|c|c|c|c|c|c|c|}
\hline \multirow[t]{2}{*}{ Life form } & \multicolumn{3}{|c|}{$\beta_{\mathrm{j}}$} & \multicolumn{3}{|c|}{$\beta_{\mathrm{s}}$} & \multicolumn{3}{|c|}{$\beta_{\text {sim }}$} \\
\hline & Factors & Cum. $R^{2}(\%)$ & AIC & Factors & Cum. $R^{2}(\%)$ & AIC & Factors & Cum. $R^{2}(\%)$ & AIC \\
\hline \multirow[t]{7}{*}{ Overall } & PC1 & 11.10 & -80.616 & PC1 & 10.90 & -50.891 & PC1 & 12.32 & -42.065 \\
\hline & PC2 & 28.10 & -85.255 & PC2 & 29.60 & -56.134 & PC2 & 37.80 & -50.095 \\
\hline & PC5 & 34.00 & -86.624 & PC5 & 35.00 & -57.362 & PC5 & 45.74 & -52.804 \\
\hline & PC6 & 36.30 & -86.753 & PC6 & 37.20 & -57.461 & PC6 & 48.48 & -53.359 \\
\hline & PCNM1 & 39.13 & -90.451 & PCNM1 & 39.96 & -61.168 & PCNM1 & 33.30 & -48.176 \\
\hline & PCNM2 & 41.13 & -90.479 & PCNM2 & 42.35 & -61.327 & PCNM3 & 34.45 & -49.732 \\
\hline & PCNM3 & 47.92 & -92.794 & PCNM3 & 48.39 & -63.361 & PCNM4 & 41.38 & -50.795 \\
\hline \multirow[t]{8}{*}{ Tree } & PC1 & 6.32 & -71.364 & PC1 & 6.60 & -42.659 & PC1 & 5.99 & -33.010 \\
\hline & PC2 & 13.61 & -71.578 & PC2 & 15.10 & -44.235 & PC2 & 20.34 & -36.432 \\
\hline & PC5 & 19.77 & -73.657 & PC5 & 20.70 & -45.193 & PC5 & 29.79 & -38.863 \\
\hline & PC6 & 27.83 & -75.618 & PC6 & 28.10 & -46.919 & PC6 & 36.70 & -40.764 \\
\hline & PCNM1 & 39.68 & -82.812 & PCNM1 & 40.95 & -54.586 & PCNM1 & 34.28 & -42.316 \\
\hline & PCNM2 & 43.77 & -83.741 & PCNM2 & 45.34 & -55.698 & PCNM2 & 38.02 & -42.949 \\
\hline & PCNM3 & 50.14 & -86.026 & PCNM3 & 51.31 & -57.863 & PCNM3 & 45.93 & -45.654 \\
\hline & & & & & & & PCNM4 & 50.70 & -47.267 \\
\hline \multirow[t]{7}{*}{ Small tree } & PC1 & 11.23 & -72.495 & PC1 & 11.12 & -43.853 & PC1 & 13.80 & -33.389 \\
\hline & PC2 & 42.73 & -82.998 & PC2 & 44.75 & -55.320 & PC2 & 49.05 & -46.165 \\
\hline & PC4 & 44.49 & -82.963 & PC4 & 46.24 & -55.187 & PC5 & 53.47 & -47.682 \\
\hline & PC5 & 49.07 & -84.412 & PC5 & 50.53 & -56.557 & & & \\
\hline & PCNM1 & 29.86 & -77.619 & PCNM1 & 30.95 & -50.415 & PCNM1 & 27.67 & -37.949 \\
\hline & PCNM2 & 30.38 & -78.921 & PCNM2 & 32.00 & -49.923 & & & \\
\hline & PCNM3 & 36.18 & -79.337 & PCNM3 & 36.83 & -50.994 & & & \\
\hline \multirow[t]{5}{*}{ Shrub } & PC1 & 11.09 & -98.995 & PC1 & 10.95 & -67.546 & PC1 & 13.51 & -57.945 \\
\hline & PC2 & 26.46 & -103.040 & PC2 & 27.30 & -71.928 & PC2 & 28.71 & -62.075 \\
\hline & PC3 & 33.55 & -104.830 & PC3 & 34.69 & -73.872 & PC3 & 32.50 & -62.649 \\
\hline & PC5 & 36.84 & -105.360 & PC5 & 37.90 & -74.391 & PC5 & 35.72 & -63.132 \\
\hline & PCNM1 & 17.76 & -101.020 & PCNM1 & 17.93 & -69.67 & PCNM1 & 18.49 & -59.484 \\
\hline
\end{tabular}

species, trees, small trees, and shrubs. These results indicated that the sampling effect hypothesis may not be applicable to the latitudinal pattern of species turnover, at least in this system. The results are inconsistent with those obtained in previous studies (Kraft et al., 2011; Myers et al., 2013; Xu et al., 2015). This inconsistency may be due to the use of latitude difference (not latitude) in our study. Latitude difference is similar to the distance between plots. The relationship between $\beta$ - and $\gamma$-diversity is complicated. Some new methods have been proposed to measure and interpret $\beta$-diversity, such as multivariate pairwise distances (Bennett and Gilbert, 2016). Therefore, further analysis is needed to distinguish the effects of $\gamma$-diversity in controlling latitudinal gradients of $\beta$-diversity.

Most ecological patterns and processes in nature are scaledependent (Bin et al., 2010; Báez et al., 2015). On a local scale, observed patterns and processes on the Changbaishan plot (Yuan et al., 2011), Lianhuachi plot (Lin et al., 2011), and Gutianshan plot (Legendre et al., 2009) showed that the diversity of forests are generally equally governed by environmental and neutral processes. On a large scale, Wang et al. (2012b) showed that spatial rather than environmental processes were the primary determinants for the latitudinal gradient in $\beta$-diversity of woody species in China. Qian et al.
(2005) studied eastern Asia and eastern North America and found that environmental and neutral processes contributed equally to latitudinal $\beta$-diversity. Our results supported the hypothesis that the effect of neutral processes on species turnover of woody species in East Asia is more important than that of environmental processes. Moreover, our results are consistent with those of Wang et al. (2012b). This is likely because the study areas in our study and Wang et al. (2012b) are the same. Our study area and the obtained topographical environment characteristics have greater difference with the study of Qian et al. (2005). Therefore, our results are not consistent with those of Qian et al. (2005), but our results are not exact opposites.

The mechanisms causing patterns of species turnover may differ among trees, small trees, and shrubs (Qian, 2009; Guèze et al., 2013). This study shows that the effect of neutral processes is more important than environmental processes for trees, and that the effects of the environment for trees are minimal. However, the effects of the environment are more important than neutral processes for shrubs, and the effects of environmental factors on shrubs are greatest among trees, small trees, and shrubs. These findings may be because the dispersal abilities, such as shape, weight, number, and germination period of seeds, vary 
A
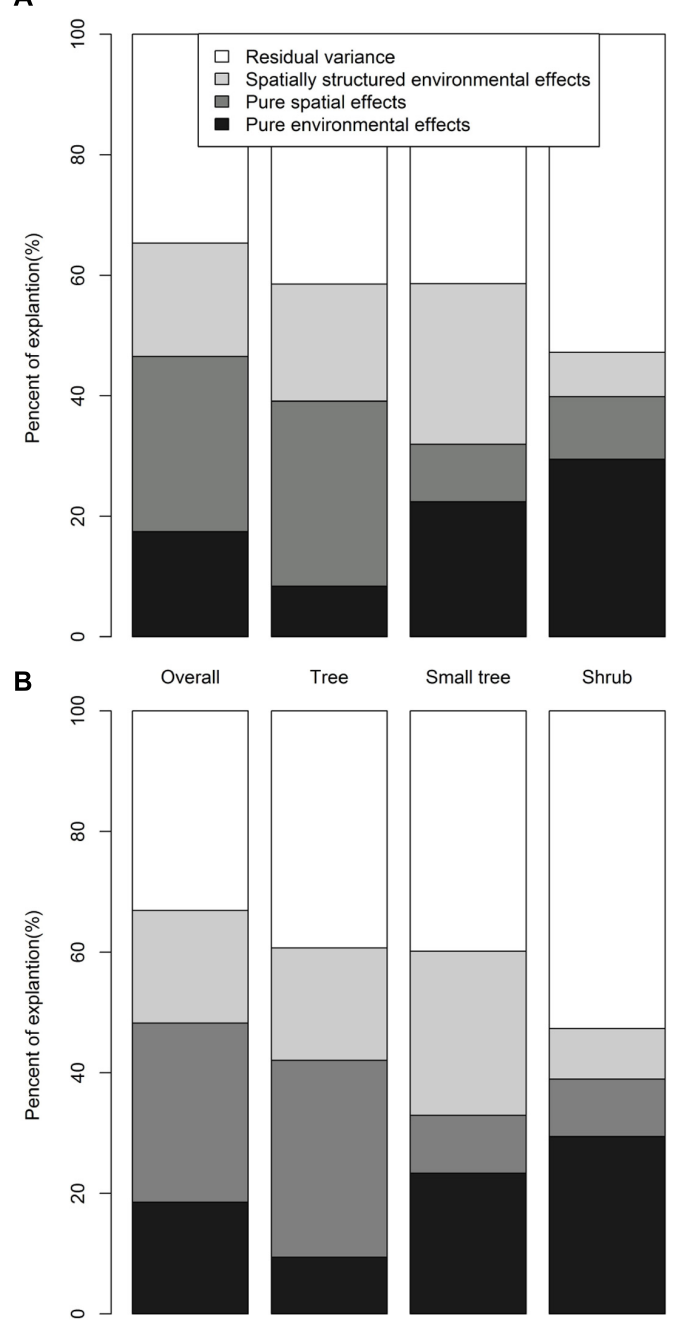

Tree

Small tree

Shrub
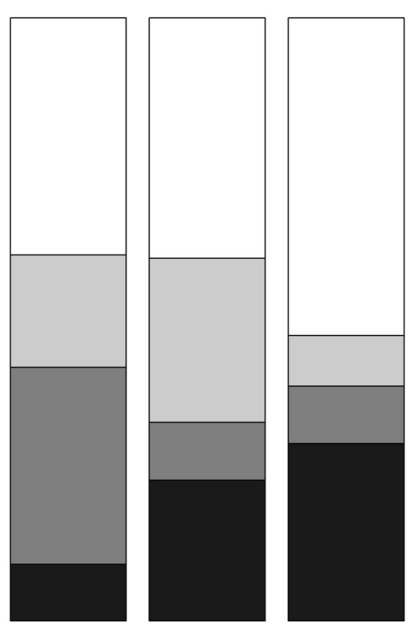

C

C

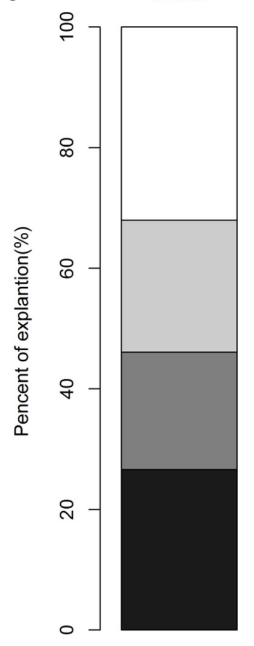

Overall
Tree

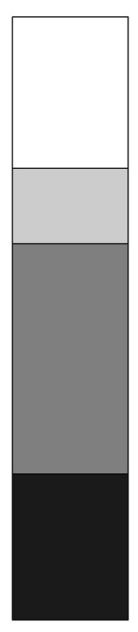

Tree
Small tree

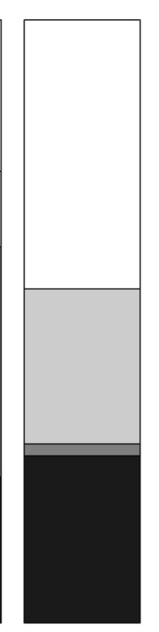

Small tree
Shrub

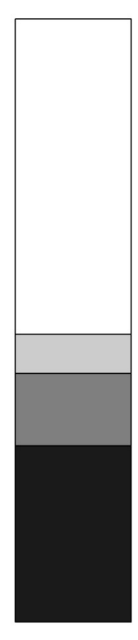

Shrub

FIGURE 6 | Partial regression analyses for the effects of environmental and spatial processes on the (A) $\beta_{j}$, (B) $\beta_{s}$, and (C) $\beta_{\text {sim }}$ of species composition.

among trees, small trees, and shrubs (Qian, 2009; Farrell et al., 2012). This phenomenon is also related to shrubs being more dependent on the local environmental heterogeneity (such as aspect and humidity) and canopy species distribution than other plants (Kristiansen et al., 2012). Thus, trees are more affected by neutral processes, and shrubs are more affected by environmental processes. These results contrast with the findings obtained by Guèze et al. (2013), who determined that environmental processes explained more variation for large trees than for small trees. This discrepancy may result partly from the use of spatial extents and environmental variables in the two studies. Guèze et al. (2013) focused only on seven villages in the southwestern Amazon and only used soil factors as environmental variables. By comparison, our study covered 184 ha plots and three temperature belts in East Asia. In particular, our environmental variables included climatic and topographical factors. Thus, at a large scale, neutral processes explained more variation for turnover of tree species, and environmental processes explained more variation for turnover of shrub species.

Chang et al. (2013) studied a subtropical broad-leaved plot in Taiwan and showed that better environmental data could reverse the conclusions about community assembly processes. Furthermore, this conclusion is also supported by some studies (Jia et al., 2015). In this study, environmental variables included climate and topographical factors. Soil, as one of the important environmental factors, was not considered. However, previous studies found that soil variables influence species distribution at small spatial extents (Sarr et al., 2005). Moreover, light environmental processes and soil microorganisms are two important factors that are often ignored in community ecology studies. Therefore, future research should consider more and better environmental factors and distinguish the effects of neutral and environmental processes on a community assembly.

\section{CONCLUSION}

The patterns of woody species turnover increased significantly with increasing latitude differences in East Asia. Our results support the hypothesis that the effect of neutral processes is more important than the effect of environmental processes on species turnover of woody species. However, the mechanisms underlying such patterns of species turnover may differ among trees, small trees, and shrubs. Neutral processes explained more variation for turnover of tree species. Environmental processes explained more variation for turnover of shrub species at a large scale. Therefore, trees and shrubs should receive different protection strategies in future biodiversity conservation efforts.

\section{AUTHOR CONTRIBUTIONS}

YY originally formulated the idea, YC and ZY developed methodology, PL, RC and HJ conducted fieldwork, YC and ZY performed statistical analyses and wrote the manuscript. 


\section{REFERENCES}

Aiello-Lammens, M. E., Slingsby, J. A., Merow, C., Mollmann, H. K., EustonBrown, D., Jones, C. S., et al. (2016). Processes of community assembly in an environmentally heterogeneous, high biodiversity region. Ecography 39, 1-16. doi: 10.1111/ecog.01945

Anderson, M. J., Crist, T. O., Chase, J. M., Vellend, M., Inouye, B. D., Freestone, A. L., et al. (2011). Navigating the multiple meanings of $\beta$ diversity: a roadmap for the practicing ecologist. Ecol. Lett. 14, 19-28. doi: 10.1111/j.14610248.2010.01552.x

Báez, S., Malizia, A., Carilla, J., Blundo, C., Aguilar, M., Aguirre, N., et al. (2015). Large-scale patterns of turnover and basal area change in Andean forests. PLoS ONE 10:e0126594. doi: 10.1371/journal.pone.0126594

Bennett, J. R., and Gilbert, B. (2016). Contrasting beta diversity among regions: how do classical and multivariate approaches compare? Global Ecol. Biogeogr. 25, 368-377. doi: 10.1111/geb.12413

Bin, Y., Wang, Z., Wang, Z., Ye, W., Cao, H., and Lian, J. (2010). The effects of dispersal limitation and topographic heterogeneity on beta diversity and phylobetadiversity in a subtropical forest. Plant Ecol. 209, 237-256. doi: 10.1007/s11258-009-9708-y

Blanchet, F. G., Legendre, P., and Borcard, D. (2008). Forward selection of explanatory variables. Ecology 89, 2623-2632. doi: 10.1890/07-0986.1

Catalogue of Life China (2013). The Biodiversity Committee of the Chinese Academy of Sciences. Catalogue of Life China 2013 Annual Checklist, CD-Rom. Beijing: Science Press.

Chang, L. W., Zelený, D., Li, C. F., Chiu, S. T., and Hsieh, C. F. (2013). Better environmental data may reverse conclusions about niche-and dispersal-based processes in community assembly. Ecology 94, 2145-2151. doi: 10.1890/122053.1

De Cáceres, M., Legendre, P., Valencia, R., Cao, M., Chang, L. W., Chuyong, G., et al. (2012). The variation of tree beta diversity across a global network of forest plots. Glob. Ecol. Biogeogr. 21, 1191-1202. doi: 10.1111/j.14668238.2012.00770.x

Elgar, A. T., Freebody, K., Pohlman, C. L., Shoo, L. P., and Catterall, C. P. (2014) Overcoming barriers to seedling regeneration during forest restoration on tropical pasture land and the potential value of woody weeds. Front. Plant Sci. 5:200. doi: 10.3389/fpls.2014.00200

Erickson, D. L., Jones, F. A., Swenson, N. G., Pei, N., Bourg, N. A., Chen, W., et al. (2014). Comparative evolutionary diversity and phylogenetic structure across multiple forest dynamics plots: a mega-phylogeny approach. Front. Genet. 5:358. doi: 10.3389/fgene.2014.00358

Escudero, A., and Valladares, F. (2016). Trait-based plant ecology: moving towards a unifying species coexistence theory. Oecologia 180, 919-922. doi: 10.1007/s00442-016-3578-5

Fang, J., Shen, Z., Tang, Z., Wang, X., Wang, Z., Feng, J., et al. (2012). Forest community survey and the structural characteristics of forests in China. Ecography 35, 1059-1071. doi: 10.1111/j.1600-0587.2013.00161.x

Farrell, C., Hobbs, R. J., and Colmer, T. D. (2012). Microsite and litter cover effects on seed banks vary with seed size and dispersal mechanisms: implications for revegetation of degraded saline land. Plant Ecol. 213, 1145-1155. doi: 10.1007/s11258-012-0072-y

Gaston, K. J. (2000). Global patterns in biodiversity. Nature 405, 220-227. doi: $10.1038 / 35012228$

Guèze, M., Paneque-Gálvez, J., Luz, A. C., Pino, J., Orta-Martínez, M., ReyesGarcía, V., et al. (2013). Determinants of tree species turnover in a southern Amazonian rain forest. J. Veg. Sci. 24, 284-295. doi: 10.1111/j.16541103.2012.01461.x

Hao, Z. Q., Li, B. H., Zhang, J., Wang, X. G., and Ye, J. (2008). Broad-leaved korean pine (pinus koraiensis) mixed forest plot in Changbaishan (CBS) of China: community composition and structure. Chin. J. Plant Ecol. 32, $238-250$.

Harms, K. E., Condit, R., Hubbell, S. P., and Foster, R. B. (2001). Habitat associations of trees and shrubs in a 50-ha Neotropical forest plot. J. Ecol. 89, 947-959. doi: 10.1111/j.1365-2745.2001.00615.x

Hubbell, C. S. (2001). A Unified Theory of Biodiversity and Biogeography. Princeton, NJ: Princeton University Press.

Jaccard, P. (1912). The distribution of the flora in the alpine zone. New Phytol. 11, 37-50. doi: 10.1111/j.1469-8137.1912.tb05611.x
Jia, H. R., Chen, Y., Yuan, Z. L., Ye, Y. Z., and Huang, Q. C. (2015). Effects of environmental and spatial heterogeneity on tree community assembly in Baotianman National Nature Reserve, Henan, China. Pol. J. Ecol. 63, 175-183. doi: 10.3161/15052249PJE2015.63.2.002

Jost, L. (2007). Partitioning diversity into independent alpha and beta components. Ecology 88, 2427-2439. doi: 10.1890/06-1736.1

Koleff, P., Gaston, K. J., and Lennon, J. J. (2003). Measuring beta diversity for presence-absence data. J. Anim. Ecol. 72, 367-382. doi: 10.1046/j.13652656.2003.00710.x

Kraft, N. J., Comita, L. S., Chase, J. M., Sanders, N. J., Swenson, N. G., Crist, T. O., et al. (2011). Disentangling the drivers of $\beta$ diversity along latitudinal and elevational gradients. Science 333, 1755-1758. doi: 10.1126/science.1208584

Kreft, H., and Jetz, W. (2007). Global patterns and determinants of vascular plant diversity. Proc. Natl. Acad. Sci. U.S.A. 104, 5925-5930. doi: 10.1073/pnas.0608361104

Kristiansen, T., Svenning, J. C., Eiserhardt, W. L., Pedersen, D., Brix, H., Munch Kristiansen, S., et al. (2012). Environment versus dispersal in the assembly of western Amazonian palm communities. J. Biogeogr. 39, 1318-1332. doi: 10.1111/j.1365-2699.2012.02689.x

Lan, G. Y., Hu, Y. H., Cao, M., Zhu, H., Wang, H., Zhou, S.-S., et al. (2008). Establishment of Xishuangbanna tropical forest dynamics plot: species compositions and spatial distribution patterns. Chin. J. Plant Ecol. 32, 287-298.

Legendre, P., Mi, X., Ren, H., Ma, K., Yu, M., Sun, I., et al. (2009). Partitioning beta diversity in a subtropical broad-leaved forest of China. Ecology 90, 663-674. doi: 10.1890/07-1880.1

Lennon, J. J., Koleff, P., Greenwood, J. J. D., and Gaston, K. J. (2001). The geographical structure of British bird distributions: diversity, spatial turnover and scale. J. Anim. Ecol. 70, 966-979. doi: 10.1046/j.0021-8790.2001.00563.x

Lin, Y. C., Chang, L. W., Yang, K. C., Wang, H. H., and Sun, I. F. (2011). Point patterns of tree distribution determined by habitat heterogeneity and dispersal limitation. Oecologia 165, 175-184. doi: 10.1007/s00442-010-1718-X

Liu, X., Swenson, N. G., Lin, D., Mi, X., Umaña, M. N., Schmid, B., et al. (2016) Linking individual-level functional traits to tree growth in a subtropical forest. Ecology 97, 2396-2405. doi: 10.1002/ecy.1445

Liu, Y., Tang, Z., and Fang, J. (2015). Contribution of environmental filtering and dispersal limitation to species turnover of temperate deciduous broad-leaved forests in China. Appl. Veg. Sci. 18, 34-42. doi: 10.1111/avsc.12101

Morin, X., and Lechowicz, M. J. (2013). Niche breadth and range area in North American trees. Ecography 36, 300-312. doi: 10.1111/j.1600-0587.2012.07340.x

Myers, J. A., Chase, J. M., Jiménez, I., Jørgensen, P. M., Araujo-Murakami, A., Paniagua-Zambrana, N., et al. (2013). Beta-diversity in temperate and tropical forests reflects dissimilar mechanisms of community assembly. Ecol. Lett. 16, 151-157. doi: 10.1111/ele.12021

Oksanen, J., Kindt, R., Legendre, P., O’Hara, B., Stevens, M. H. H., Oksanen, M. J., et al. (2007). The vegan package. Commun. Ecol. Package 2007, 631-637.

Qian, H. (2009). Beta diversity in relation to dispersal ability for vascular plants in North America. Global Ecol. Biogeogr. 18, 327-332. doi: 10.1111/j.14668238.2009.00450.x

Qian, H., Badgley, C., and Fox, D. L. (2009). The latitudinal gradient of beta diversity in relation to climate and topography for mammals in North America. Glob. Ecol. Biogeogr. 18, 111-122. doi: 10.1111/j.1466-8238.2008.00415.x

Qian, H., and Ricklefs, R. E. (2007). A latitudinal gradient in large-scale beta diversity for vascular plants in North America. Ecol. Lett. 10, 737-744. doi: 10.1111/j.1461-0248.2007.01066.x

Qian, H., and Ricklefs, R. E. (2008). Global concordance in diversity patterns of vascular plants and terrestrial vertebrates. Ecol. Lett. 11, 547-553. doi: 10.1111/j.1461-0248.2008.01168.x

Qian, H., Ricklefs, R. E., and White, P. S. (2005). Beta diversity of angiosperms in temperate floras of eastern Asia and eastern North America. Ecol. Lett. 8, 15-22. doi: 10.1111/j.1461-0248.2004.00682.x

Rodríguez, P., and Arita, H. T. (2004). Beta diversity and latitude in North American mammals: testing the hypothesis of covariation. Ecography 27, 547556. doi: 10.1111/j.0906-7590.2004.03788.x

Sarr, D. A., Hibbs, D. E., and Huston, M. A. (2005). A hierarchical perspective of plant diversity. Q. Rev. Biol. 80, 187-212. doi: 10.1086/433058

Song, Y. C., Yan, E. R., and Song, K. (2015). Synthetic comparison of eight dynamics plots in evergreen broadleaf forests, China. Biodivers. Sci. 23, 139-148. doi: 10.17520 /biods. 2014140 
Sorensen, T. (1948). A method of establishing groups of equal amplitude in plant sociology based on similarity of species content. Kongelige Danske Videnskabernes Selskab 5, 4-7.

Stuart, Y. E., Losos, J. B., and Algar, A. C. (2012). The island-mainland species turnover relationship. Proc. R. Soc. Lond. B Biol. Sci. 279, 4071-4077. doi: 10.1098/rspb.2012.0816

Su, S. H., Chang-Yang, C. H., Lu, C. L., Tsui, C. C., Lin, T. T., et al. (2007). Fushan Subtropical Forest Dynamics Plot: Tree Species Characteristics and Distribution Patterns. Taipei: Taiwan Forestry Research Institute.

Tang, Z., Fang, J., Chi, X., Feng, J., Liu, Y., Shen, Z., et al. (2012a). Patterns of plant beta-diversity along elevational and latitudinal gradients in mountain forests of China. Ecography 35, 1083-1091. doi: 10.1111/j.1600-0587.2012.06882.x

Tang, Z., Fang, J., Chi, X., Yang, Y., Ma, W., Mohhamot, A., et al. (2012b). Geography, environment, and spatial turnover of species in China's grasslands. Ecography 35, 1103-1109. doi: 10.1111/j.1600-0587.2012.07713.x

Valencia, R., Foster, R. B., Villa, G., Condit, R., Svenning, J. C., Hernández, C., et al. (2004). Tree species distributions and local habitat variation in the Amazon: large forest plot in eastern Ecuador. J. Ecol. 92, 214-229. doi: 10.1111/j.00220477.2004.00876.x

Valladares, F., Bastias, C. C., Godoy, O., Granda, E., and Escudero, A. (2015). Species coexistence in a changing world. Front. Plant Sci. 6:866. doi: 10.3389/fpls.2015.00866

Wang, Z., Fang, J., Tang, Z., and Lin, X. (2012a). Relative role of contemporary environment versus history in shaping diversity patterns of China's woody plants. Ecography 35, 1124-1133. doi: 10.1111/j.1600-0587.2011. 06781.x

Wang, Z., Fang, J., Tang, Z., and Shi, L. (2012b). Geographical patterns in the beta diversity of China's woody plants: the influence of space, environment and range size. Ecography 35, 1092-1102. doi: 10.1111/j.1600-0587.2012. 06988.x

Xu, W., Chen, G., Liu, C., and Ma, K. (2015). Latitudinal differences in species abundance distributions, rather than spatial aggregation, explain betadiversity along latitudinal gradients. Glob. Ecol. Biogeogr. 24, 1170-1180. doi: 10.1111/geb.12331

Yang, Q. S., Ma, Z. P., Xie, Y. B., Zhang, Z. G., Wang, Z. H., et al. (2011). Community structure and species composition of an evergreen broadleaved forest in Tiantong's 20 ha dynamic plot, Zhejiang Province, eastern China. Biodivers. Sci. 19, 215-223.

Yuan, Z., Gazol, A., Wang, X., Lin, F., Ye, J., Bai, X., et al. (2011). Scale specific determinants of tree diversity in an old growth temperate forest in China. Basic Appl. Ecol. 12, 488-495. doi: 10.1016/j.baae.2011.07.008

Zhu, Y., Zhao, G. F., Zhang, L. W., Shen, G. C., Mi, X. C., Ren, H., et al. (2008). Community composition and structure of Gutianshan forest dynamic plot in a mid-subtropical evergreen broad-leaved forest, east China. Chin. J. Plant Ecol. $32,262-273$.

Conflict of Interest Statement: The authors declare that the research was conducted in the absence of any commercial or financial relationships that could be construed as a potential conflict of interest.

Copyright (C) 2016 Chen, Yuan, Li, Cao, Jia and Ye. This is an open-access article distributed under the terms of the Creative Commons Attribution License (CC BY). The use, distribution or reproduction in other forums is permitted, provided the original author(s) or licensor are credited and that the original publication in this journal is cited, in accordance with accepted academic practice. No use, distribution or reproduction is permitted which does not comply with these terms. 